\title{
On Ways of Expressing Persuasion in Discourse
}

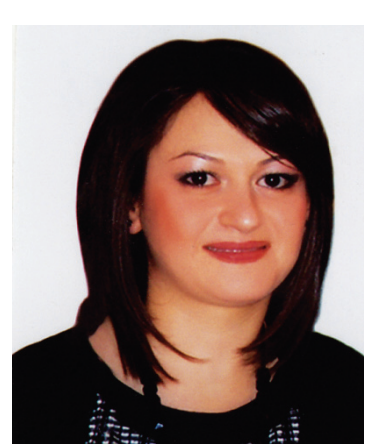

Siranoush Ghaltkhchyan
To be human is to want change. There are, of course, 1 a huge number of ways of making an influence on people's mind or behavior and changing their attitudes, beliefs or behavior. But the most frequently used and the most effective tool that people manipulate to achieve change during their interaction is persuasion.

Interest in developing some general principles of persuasion is not new. In the fourth century BC Aristotle concerned himself with the persuasive communication and identified three kinds of persuasion: "Of the modes of persuasion furnished by the spoken word there are three kinds. The first kind depends on the personal character of the speaker; the second on putting the audience into a certain frame of mind; the third on the proof, provided by the words of the speech itself. [...] persuasion may come to the hearers when a speech stirs their emotions. Secondly, persuasion is affected through the speech itself when we have proved a truth or an apparent truth by means of the persuasive arguments suitable to the case in question" (Petty 1981:5).

The American social psychologist J.W. Zanden defines persuasion as "a deliberate attempt on the part of one party to influence the attitudes or behavior of the other party, so as to achieve some predetermined end" (Zanden 1977:11). In writing about persuasive speaking T.S. Scheider states that it can be described to be that activity in which the speaker and the listener are "conjoined" and in which the speaker consciously attempts to influence the behaviour of the listener by "transmitting audible and visible symbolic cues" (Scheidel 1985).

A careful and detailed investigation makes it possible to give a more or less complete definition of the persuasive communication. Any conscious, deliberate and predetermined attempt of an individual to make certain changes in the interlocutor's cognition or behaviour, i.e. to make the interlocutor adhere to his/her own point of view through the transmission of some message can be considered to be a persuasive behaviour. Whenever some changes are apparent in part of the recipient in favour of the message, the process of persuading can be viewed as successful. What is important here is that how E.P. Bettinghaus notes "success in persuasive communication must be based on a series of decisions, each having its roots in the central question of what is best for mankind" (Bettinghaus 1980:7).

The aim of this paper is to bring together and analyze different theories on persuasive communication taking into account the theory of speech acts and the theory of conversational implicature. Our task is to attempt to discover first of all the basic features of persuasive communication, the necessary conditions of its effectiveness. We shall try to place emphasis on the different means and strategies that different people may choose to use in order to achieve an effective end in persuasive communicative situations. 
The in-depth investigation of various persuasive communicative situations comes to prove that persuasion is not only a linguistic but also a psychological action. To approach the problem it would be preferable to cast a brief glance at the psychological aspect of persuasive communication that will consequently lead us to a better understanding of the complex nature of persuasive communication. For a communicator to satisfy his/her communicative needs and to be a success in a persuasive communication, s/he should necessarily take into consideration and observe the psychological factors of persuasion.

In any persuasive communicative situation a formula is always apparent that should be necessarily observed in order to understand the process properly. That is 'who says what to whom and how'. These are accordingly four basic factors engaged in the process of communication: the source (who says it), the message (what is said), the recipient (to whom it is said), and the channel (medium or means of communication). The interrelation among these factors may produce persuasion. When situations become more and more complicated, these factors necessarily remain, though there may be circumstances with more than one source, more than one receiver, many different messages and various channels. Most of the time the process of persuasion takes place in the following way: the persuasive context, i.e. the source and the message, question the receiver's initial attitude, recommend the adoption of a new attitude and provide 'incentives' for understanding, yielding to and retaining the new rather than the initial attitude.

Each of these factors is of great importance and all of them do play certain role in affecting the effectiveness of a persuasive intent and can greatly account for persuasive changes. In his meditations about persuasion Plato puts to the fore the importance of the message factor in any persuasive communication. He regarded persuasion as the key to power and the message as the key to persuasion. "What is there greater than the word which persuades the judges in the court, or the senator in the council, or the citizen in the assembly, or at any other meeting? - if you have the power of uttering this word, you will have any person your slave. Even the money maker of whom you talk will be found to gather treasures, not for himself, but for you, who are able to speak and to persuade the multitude" (Petty 1981: 69).

Nevertheless, the most significant and the most decisive role in any persuasive communicative situation belongs to the source factor, for, it is up to the sender of the massage to determine how to organize his/her persuasive speech, how to construct the structure and the stylistic design of the message to conduct persuasion. Moreover, along with verbal communication the source may make use of the so-called extralinguistic cues or paralinguistic means that include gestural and postural system, intonation, spatial distance from the receiver, rate of speech, length and frequency of pauses, eye contact and so on. Such non-verbal cues are generally very informative. They may add a new dimension to the given verbal message and contribute greatly to the total purport of the persuasive massage. In many persuasive communicative situations the effectiveness of a persuasive attempt may be very much dependent even upon the source's appearance, social status, lifestyle, age, sex, relationship to the receiver, manner of dressing and behaving, approaches to this or that phenomenon or to life in general.

The belief that the source of the message acquires great significance in any persuasive 
communication can be traced back to Aristotle who wrote that "persuasion is achieved by the speaker's personal character when the speech is so spoken as to make us think him credible. We believe a good man more fully and more readily than others. It is not true, as some writers assume in their treatises on rhetoric, that the personal goodness revealed by the speaker contributes nothing to his power of persuasion; on the contrary, his character may always be called the most effective means of persuasion he possesses" (Roberts 1886: 7).

So, one of the most straightforward findings of the investigations on persuasion is that the higher a person's evaluation of the communicator, i.e. source, the more likely is s/he to yield to the persuasive communication. The two major elements in the target individual's evaluation of a communicator are the source's credibility, i.e. certain perceptions about the source held by the recipient and the source's attractiveness to the recipient, i.e. the degree to which the communicator is liked by the target individual. Hence, high-credibility communicators are more effective in producing attitude change than low-credibility communicators are and the better the communicator's appearance, style of speaking, gestural and postural system the more persuasive s/he may be (Bettinghaus1980).

Nevertheless, the recipient factor is not less important in the process of persuasion, for, in many cases the failure or success in a specific persuasive communicative situation may depend greatly on the receiver of the massage. J.W.Zanden notes in this connection that there are two main kinds of people. Some people are gullible pushovers, while others stubbornly stick to their guns (Zanden 1977). Attention should be focused on such factors as age, gender, intelligence of the recipient. Zellner suggest the importance of self-esteem which is positively related to intelligence. Self-esteem refers to the value, worth or regards one places on himself/herself. It has been proved that people with low self-esteem are less confident and less competent, view themselves as less capable than people with high self-esteem. Consequently, an individual with low self-esteem is usually more persuasible, i.e. more easily persuaded than an individual with high self-esteem. "What you think of yourself will much depend upon the degree to which your actual successes coincide with the goals and aspirations you have set for yourself" (Bettinghaus 1980:54). Skolnick and Keslin develop the idea that addressees high in the "need for social approval", i.e. the desire to be liked by others, are often easier to influence than individuals lower in this need (Shaver 1977).

If we investigate the problem from the pragmalinguistic angle the massage factor comes to the fore. It is a well-proved fact that most of the time sentences uttered are not just "innocent statements", that utterances in addition to the semantic meaning they convey perform specific actions, i.e. the interlocutors do things with words in particular speech situations either consciously or subconsciously (Austen 1969). Independent of syntactic and semantic categories, utterances can be used to mean different things in different contexts depending on how they relate to the context or speech event in which they are uttered. Thus, it is likely that the sentences uttered have a finite set of functions, speech acts that sometimes may even convey meaning opposite to the sentence meaning (Searle 1976).

J.L. Austen goes on stating that any linguistic string uttered or proposition, i.e. a locutionary act may possess a specific intention or function, i.e. illocutionary act which is intended on the part of the addresser to have an effect of some kind on the addressee, i.e. perlocutionary effect (Austen 1969). It should be noted in this connection that the 
communicator should know what to utter and how in the specific context to get the wanted perlocutionary effect. In the P.H. Grice's theory this implies to the conventional implicature which can be defined as the literal truth condition of the utterance and conversational implicature which provides some explicit account of how it is possible to mean more than what is literally expressed by the conventional sense of the linguistic expression uttered (Grice 1975). With this regard the notion of implicit and explicit utterances is introduced. What is said is the literal, explicit meaning and what is meant or implicated is the implicit meaning of an utterance, the second being solely dependent upon a particular context and the general background knowledge of the interlocutors.

Hence, if persuasive communication is investigated from the pragmalinguistic angle, we can surely state that persuasion can be described as a perlocutionary act, the effect of some linguistic behaviour and we have to admit that there exist two basic ways of making an influence and changing the interlocutor's standpoint: explicit and implicit.

Some communicators prefer to be straightforward while speaking and command their wish explicitly, letting the recipient obviously realize their communicative intent. To make the point clear let us firstly observe a set of interesting examples.

Come Fanny, these are fine times for you, but you must not be always walking from one room to the other and doing the looking on, at your ease, in this way,- I want you here.- I have been slaving myself till I can hardly stand." Fanny took the work very quietly without attempting any defense. (J. Austen: 120)

What a piece of work here is about nothing,- I am quite ashamed of you, Fanny, to make such a difficulty of obliging your cousin in a trifle of this sort, -so kind as they are to you!- Take the part with a good grace, and let us hear no more of the matter. (J. Austen: 170)

Fanny now that you are going into company without any of us; I do beseech and entreat you not to be putting yourself forward, and talking and giving your opinion as if you were one of your cousins - as if you were dear Mrs. Rushworth or Julia. That will never do, believe me. Remember, wherever you are, you must be the lowest and last, and as to coming away at night, you are to stay just as long as Edmund chooses. Leave him to settle that. (J. Austen: 158)

Stay, stay Fanny! What are you about? - Where are you going? - don't be in such a hurry. Depend upon it, it is not you that are wanted; depend upon it, it is me, but you are so very eager to put yourself forwards. What should Sir. Thomas want you from? It is me, Baddeley, you mean, I am coming this moment. You mean me, Baddeley, I am sure, Sir Thomas wants me, not Miss Price. (J. Austen: 84)

As we see, in these examples the act of persuasion may sound synonymous to such directive acts as requesting, questioning, ordering, instructing, urging etc. We come to 
realize or presuppose that these are persuasive attempts when we take into account the context of the speech acts, for, it is the nature of the speech event that determines the kind of speech act of an utterance. Otherwise, these utterances can be regarded as infelicitous or inappropriate. So, the communicators apply to the illocutionary force of requesting, questioning, ordering to have the perlocutionary effect of persuasion. Though, actually, the directives 'beseech', 'entreat' are used in one of the examples, they are uttered in such a tone that it becomes apparent that they mean just the opposite. The emphatic use of inverted word order in the sentence contributes greatly to the same stylistic effect.

The studies have shown that those communicators who resort constantly to explicit persuasion are generally middle-class people with low level of intelligence and with low level of consciousness, of dictatorial character and insolent manners, who overestimate their 'wisdom' and 'intelligence' and are always convinced of their 'truthfulness'.

Not less important is also the recipient factor. Explicit persuasion is mostly exposed upon addressees with low self-esteem, of humble and submissive nature and, what is more important, of a lower social level.

Nevertheless, explicit persuasion, as a rule, decreases the effectiveness of a persuasive message to a great extent and reduces the chances to succeed in persuasion. Hence, the source's persuasive attempts in case of explicit persuasion almost always end in failure. Fortunately enough, the instances of explicit persuasion expressed through imperative sentences are not very frequently observed in discourse, for, in their form and structure such speeches used in any persuasive communicative situation sound rather rude, impolite and inadequate and may only hinder an effective communication.

Communicators more frequently choose the implicit way of convincing, when an attempt is made by the source to measure and alter the recipient's initial attitude, belief or behaviour, disguising his/her real intention, trying to persuade the other party in an indirect way as if advising, encouraging, complimenting or just giving information. The choice of the way of persuading is much conditioned by not only the addresser of the message but also and mainly by the addressee of the massage, his/her age, gender and, what is of utmost importance, of the self-esteem and intelligence of the receiver. It has been proved that more intelligent addressees are more likely to be persuaded by complex messages than less intelligent ones would. The more intelligent the addressee is, the more difficult it is for the communicator to make him/her yield to the persuasive massage because of his/her greater critical faculties (Bettinghaus 1980). Hence, it is necessary to change the nature and style of the persuasive massage and resort to the implicit way of persuading when one has to do with a receiver higher in self-esteem and intelligence, since the explicit persuasion in this case is sure to fall flat.

To elucidate the point let's examine the following speech event where one of the heroines of the novel "Mansfield Park" after J.Austen, Mrs. Norris tries to persuade Sir Thomas to take care of her poor sister's daughter. The communicator's speech here is rather long, well-prepared and carefully elaborated with lots of transitions and repetitions, since Sir Thomas is an intelligent and very respected man among the upper class society and persuading him requires much strength and skills. The addresser makes use of the so-called 'sleeper effect' method, i.e. she tends to produce attitude change in 
a period of time in a brain-washing manner, prolonging her speech on purpose in order to make persuasion clandestine (Shaver 1977).

My deer Sir Thomas, I perfectly understand you and do justice to the generosity and delicacy of your notions, which indeed are quite of a piece with your general conduct; and I entirely agree with you in the main as to the propriety of doing everything one could by way of providing for a child one had in a manner taken into once own hands. [...] I thoroughly understand you; you are everything that is generous and considerate, and I am sure we shall never disagree with on this point. [...] Whatever I can do, as you well know, I am always ready enough to do for the good of those I love, and, though I could never feel for this little girl the hundredth part of the regard I bear to your own dear children, nor consider her, in any respect, so much my own, I should hate myself if I were capable of neglecting her. [...] Is not she a sister's child? And could I bare to see her want, while I had a bit of bread to give her? My dear Sir Thomas, with all my faults I have a warm heart, and, poor as I am, would rather deny myself the necessaries of life, than do an ungenerous thing. [...] I am sure I should be the last person in the world to withhold my mite upon such an occasion. Having no children of my own, who should I look to in my litter matter I may ever have to bestow, but the children of my sister? But you know I'm a woman of few words and professions. [...] Do not let us be frightened from a good deed by a trifle. Give a girl an education and introduce her properly into the world, and, ten to one but she has the means of settling well, without farther expense to anybody. A niece of ours, Sir Thomas, I may say, or, at least of yours, would not grow up in this neighbourhood without many advantages. [...] So, if you are not against it I will write to poor sister tomorrow, and make the proposal, and as soon as matters are settled I will engage to get the child to Mansfield Park, you shall have no trouble about it. My own trouble, you know, I never regard. I will send Mary to London on purpose. (J. Austen: 5-6)

So, the heroine starts her persuasive speech applying to the illocutionary force of praising and complimenting Sir Thomas on "his generosity and delicacy of his notions", on having "considerate and compassionate heart" always addressing him with the vocative "my dear Sir Thomas". So, initially it becomes difficult to presuppose that this is a persuasive attempt. As she goes on with her persuasive communication she passes to the encouraging and then to the advising method, speaking of her readiness and willingness to help those she loves as if implying that she was never reluctant to be of help as far as Sir Thomas's own children are concerned. She desires to touch upon his heart declaring that she would never trouble him on this problem unless she was rich enough and if her health was not in such a "miserable" condition. Meanwhile, she threatens Sir Thomas that it would be a rather "disgraceful and ungenerous thing" not helping his poor relative, knowing very well that Sir Thomas pays much attention to the public opinion. Then she makes her persuasive speech more powerful 
using rhetorical questions such as "Is not she a sister's child?"; "And could I bare to see her want, while I had a bit of bread to give her?; "Having no children of my own, who should I look to in my litter matter I may ever have to bestow, but the children of my sister?".

She alters the style of her speech to an extent when she goes further and gives a more decisive and compulsory colouring to her persuasive speech. This can be best illustrated by the grammatical structures of the sentences that are similar to that of imperative sentences. The persuasive intent of Mrs. Norris's speech becomes apparent not only on the syntactic level of the analysis but also on the semantic level. The specific choice of this or that word in a given speech event makes it possible for the perlocutionary effect to be more powerful. At the end of her speech the usage of the vocative without any endearment pronounced with a firmer tone of voice and the replacement of the pronoun 'ours' with the more emphatic 'yours' has the effect of stressing Sir Thomas's responsibility and obligations towards his poor relatives. In the end, we should state that all her endeavours were not in vain. Mrs. Norris accomplished her goal and managed to persuade Sir Thomas in adopting the little girl.

So, this long and carefully elaborated persuasive speech asserts the idea that there may be more than one speech act in the very same speech event, one interwoven inside the other and each of which is acceptable with respect to the previous one. This is done on purpose to reach an effective end in the persuasive communicative situation. These instances allow us to state that implicit ways of expressing the illocutionary force of the persuasive massage depend on the speaker's wish to sound more polite and avoid negative answers in reply to his persuasive massage on the one hand, and avoid communicative conflicts in case of refusal on the other hand.

To sum up, we can deduce that persuasion may be viewed as a strategy of human interaction which requires linguistic choices to be made on a wide range of languageinternal levels (phonetic, morphological, syntactic, lexical, semantic), as well as languageexternal levels, such as paralinguistic means of interaction (gestures, facial expressions, etc.) and also the illocutionary force of indirect speech acts. So, the variable range of options is extremely wide and depends on the awareness of the processes the interlocutor is involved in. Hence, persuasive communication which employs the strategy of persuasion depends largely on language adaptability in which the speaker makes linguistic choices from a variable range of options in such a way as to satisfy his/her communicative need.

\section{References:}

1. Austen, J. (1992) Mansfield Park London, Penguin Popular Classics.

2. Austin, J.L. (1962) How to Do Things with Words. London: Oxford university Press.

3. Bettinghaus, P. E. (1979) Persuasive Communication. 3-rd edition. New York.

4. Brown, P.; Levinson, C. S. (1995) Politeness: Some Universals in Language Usage Cambridge University Press.

5. Byrne, D. (1981) Social Psychology: Understanding Human Interaction, 3-rd edition. New York.

6. Grice, H. P. (1975) Logic and Conversation // Syntax and Semantics. / Ed by Cole P. and Morgan J.L. New York: Academic Press. Vol. 3. 
7. Jule, G. (1996) Pragmatics. / Ed. By Widdowson H.G. London: Oxford University Press.

8. Larson, C.U. (1988) Persuasion: Reception and Responsibility. 4-th edition. Belmond: Wardsworth Publishing Company.

9. Leech, N. G.; Short, H.M. (1981) Style in Fiction. United States of America, New York: Longman Inc.

10. Levinson, C. S. (1983) Pragmatics. Cambridge: Cambridge University Press.

11. Osgood, E. Ch.; Sebeok, A. T. (1965) Psycholinguistics: A Survey of Theory and Research Problem with Psycholinguistics. Bloomington, Ind.: Indiana University Press.

12. Petty, E. R.; Cacioppo, T. J. (1981) Attitude and Persuasion; Classic and Contemporary Approaches. United States of America.

13. Searle, J.R. Speech Acts: (1969) An Essay in the Philosophy of Language. London: Cambridge University Press.

14. Scheidel, T. (1985) Persuasive Speaking, London.

15. Shaver, G. K. (1977) Principles of Social Psychology. Cambridge.

16. Vreschueren, J. (1999) Understanding Pragmatics. New York: Oxford University Press.

17. Zanden, J. W. (1977) Social Psychology. New York.

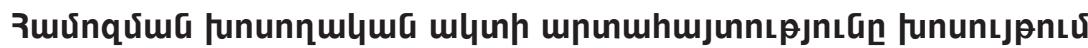

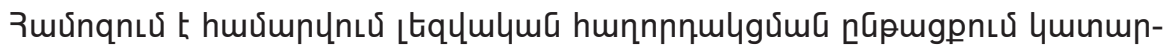

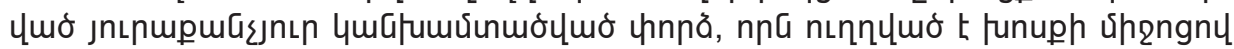

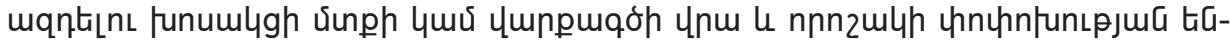

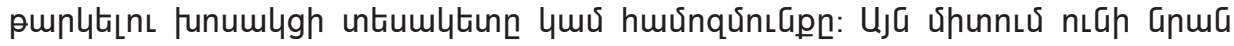

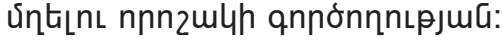

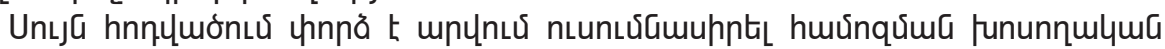

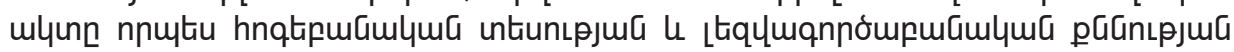

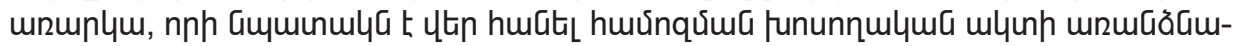

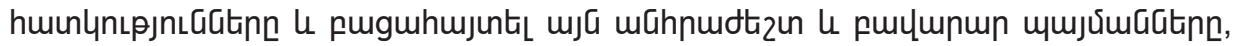

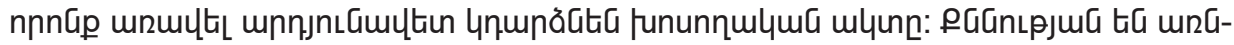

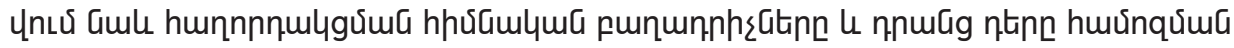

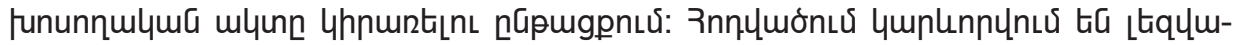

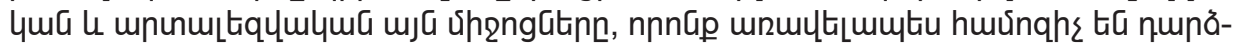

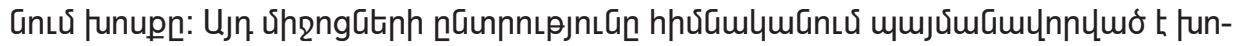

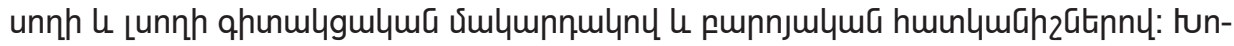

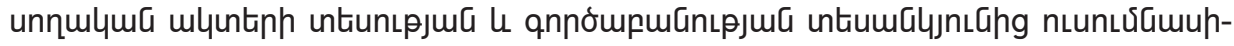

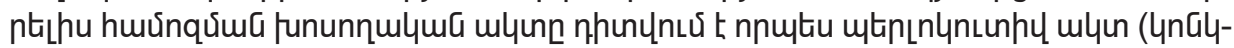

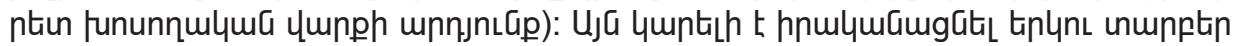

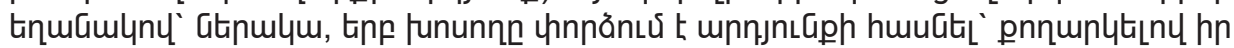

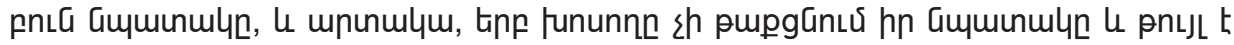

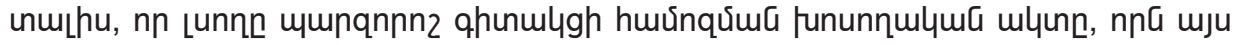

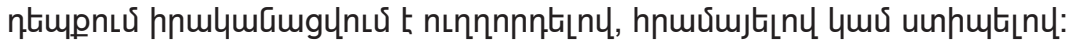

